\title{
EDITORIAL
}

\section{Revistas de investigación en la universidad}

Pedro Miguel Barrientos Felipa ${ }^{1}$

La construcción periódica de una revista de investigación de una universidad que promueve la publicación de artículos de profesores investigadores es una actividad que implica esfuerzo por parte de los miembros del Comité Editorial y por los investigadores que transforman sus resultados en artículos científicos. Ambos deben tener un comportamiento que busque el estricto cumplimiento de las normas institucionales y sociales establecidas para este caso. Además, el esfuerzo realizado permite tener la seguridad de que la tarea a realizar otorga un beneficio a la sociedad. En el caso de Perú, se reconoce que la tarea investigativa relacionada a la publicación de artículos representa limitación que afecta la inserción al mundo globalizado de las instituciones universitarias.

Se puede identificar diversos factores que forman parte del desarrollo limitado de la redacción de artículos y publicarlos en revistas académicas que sean exigentes en la aceptación para publicar los mismos, muy en especial en universidades públicas. La actual experiencia muestra a investigadores que tienen el entusiasmo de publicar los resultados de sus investigaciones, también se identifica la política gubernamental incentivando la presentación de artículos direccionándolas a repositorios de reconocimiento internacional, el esfuerzo de las revistas universitarias por continuar mejorando en la selección de los artículos a publicar, incluso aumentado su periodicidad. Todavía hay barreras que deben ser

\footnotetext{
${ }^{1}$ Economista. Vicedecano de Investigación y Posgrado de la Facultad de Ciencias Económicas de la UNMSM. Doctor en Administración de Negocios Globales. Director de la Revista Pensamiento Crítico. Dirección de correspondencia: Calle Germán Amézaga 375, Cercado, Lima, Perú.

Correo electrónico: investigacion.economia@unmsm.edu.pe
} 
superadas como el mayor involucramiento del empresariado en financiar investigaciones por la universidad, la falta de inversión en ciencia y tecnología

Son diversos los factores que influyen en esta limitación, sin embargo no significa que se esté dejando de hacer. Diversas universidades latinoamericanas están poniendo más empeño en la publicación de sus revistas que contienen artículos relacionados a la investigación. El panorama de la investigación económica se nota esperanzador, considerando que las instituciones educativas se suman con mayor ahínco a las instituciones especializadas en investigación económica. Las universidades se están adaptando al nuevo entorno, dando mayor énfasis a la investigación. La Universidad Nacional Mayor de San Marcos manifiesta en el preámbulo del Estatuto que "tiene como objetivo convertirse en una universidad de investigación, que tenga como función central la generación de conocimientos".

El objetivo citado se está generalizando en las universidades latinoamericanas, algunas yendo adelante de las demás, sin que esto signifique que los retadores busquen mantener tal posición, sino que implica un desafío por lograr una mejor posición. Por tanto, las universidades promueven entre sus profesores el incremento de la producción científica, considerando así que además de enseñar su materia correspondiente deben fortalecer su actividad de redacción de artículos basándose en investigaciones que la universidad promueve, en relación con organizaciones externas. En el otro lado, los investigadores están a la búsqueda de qué revista puede ofrecerle mejores condiciones en la publicación de sus artículos, poniendo énfasis en la evaluación de repositorios bibliográficos.

El contexto en el que ahora se desarrollan las revistas de investigación a fines de la segunda década del sigloXXI está siendo de mayor competencia por las circunstancias de las mismas universidades que promueven un mayor protagonismo. El cambio estructural afecta el caminar de los profesores universitarios al elevar su exigencia en cuanto a la producción de artículos que son revisados por pares académicos, lo que implica una mayor exigencia. La realidad permite sacar algunas conclusiones iniciales las que se detallan a continuación y que pueden haber otras a considerar: 
1. Es una tarea reciente que asumen las universidades como responsabilidad frente a la sociedad, profesores y sus alumnos.

2. Hay competencia por parte de las universidades para que los investigadores publiquen los resultados de su investigación en la revista institucional.

3. Los repositorios académicos se promueven poniendo de manifiesto sus normas para atraer a los articulistas científicos para que incluyan a la revista como una alternativa para publicación.

4. Los investigadores están en continúa evaluación de revistas que agreguen valor a los resultados de su investigación.

5. La nueva tarea permite proyectar la imagen de una institución seria que toma la investigación como un desafío permitiendo exigir mayor dedicación a sus alumnos en sus trabajos universitarios.

6. Las universidades premian a sus investigadores por publicar, otorgando puntos adicionales para su carrera docente u otros incentivos, siendo estos otorgados de acuerdo a la exigencia de los repositorios internacionales.

En este número, los artículos que se presentan abarcan las diferentes dimensiones de la ciencia económica. Este número se inicia con el artículo de Jhon Valdiglesias Oviedo, "Efectos de corto plazo de la inmigración venezolana en el Perú". A continuación expone Edwin Nahuamel Jacinto, presentan "Factores competitivos para el desarrollo de la caficultura peruana”. También contribuyen Isadora Sánchez Torné, Macarena Pérez Suárez Y Juan Carlos Morán Álvarez con “España y Rusia: factores inciertos para hacer negocios”. Sigue Álvaro Sánchez Mercado, "Logísticas internacional de mercancías y su contribución en el desarrollo nacional: factores que impulsan su desarrollo". También participa Oscar Sarango Cruz con su artículo "Construcción del megaterminal transporte multimodal para el cumplimiento del plan 2008 - 2021 Región Lima”. Los investigadores Neisser Pino Romero y Frank Acasiete Quispe presentan "Percepción de la formación y exigencia académica de los docentes universitarios enfocada al impulso de la investigación científica". Héctor Acuña Arone aporta su artículo "Hipótesis de desacople en la economía 
peruana desde el período 2000 - 2016. Rolando Molina Bocangel expone sus resultados de investigación a través del artículo "La inversión en la educación en Madre de Dios". Jorge Osorio Vaccaro con "¿Intercambio compensado entre inflación y desempleo? El Estado como empleador directo". Raimundo Pacheco Mexzon presenta "Roe y estructura financiera de las empresas mineras periodo 2004 - 2013". Hoover Ríos Zuta contribuye con "Libre comercio y apertura comercial en la Alianza del Pacifico e impacto económico: período 1970 - 2015". Se concluye con Pablo Rivas Santos y su artículo "Algunas notas sobre el método de la economía y el método de la investigación científica". 